\title{
A freaky artery
}

\section{R. Joustra' · A. P. J. van Dijk' • H. W. J. Meijburg' ${ }^{2}$ M. Boulaksil' ${ }^{1}$}

Published online: 22 October 2018

(c) The Author(s) 2018

A 77-year-old male patient, with an irrelevant cardiovascular history, was referred to our hospital with acute severe interscapular pain arising at rest. A computed tomography angiography (CTA) was performed (Fig. 1a, b). What is your diagnosis?

\section{Answer}

You will find the answer elsewhere in this issue.

Open Access This article is distributed under the terms of the Creative Commons Attribution 4.0 International License (http:// creativecommons.org/licenses/by/4.0/), which permits unrestricted use, distribution, and reproduction in any medium, provided you give appropriate credit to the original author(s) and the source, provide a link to the Creative Commons license, and indicate if changes were made.
Fig. 1 a Transversal CT section of our patient. b Sagittal CT section
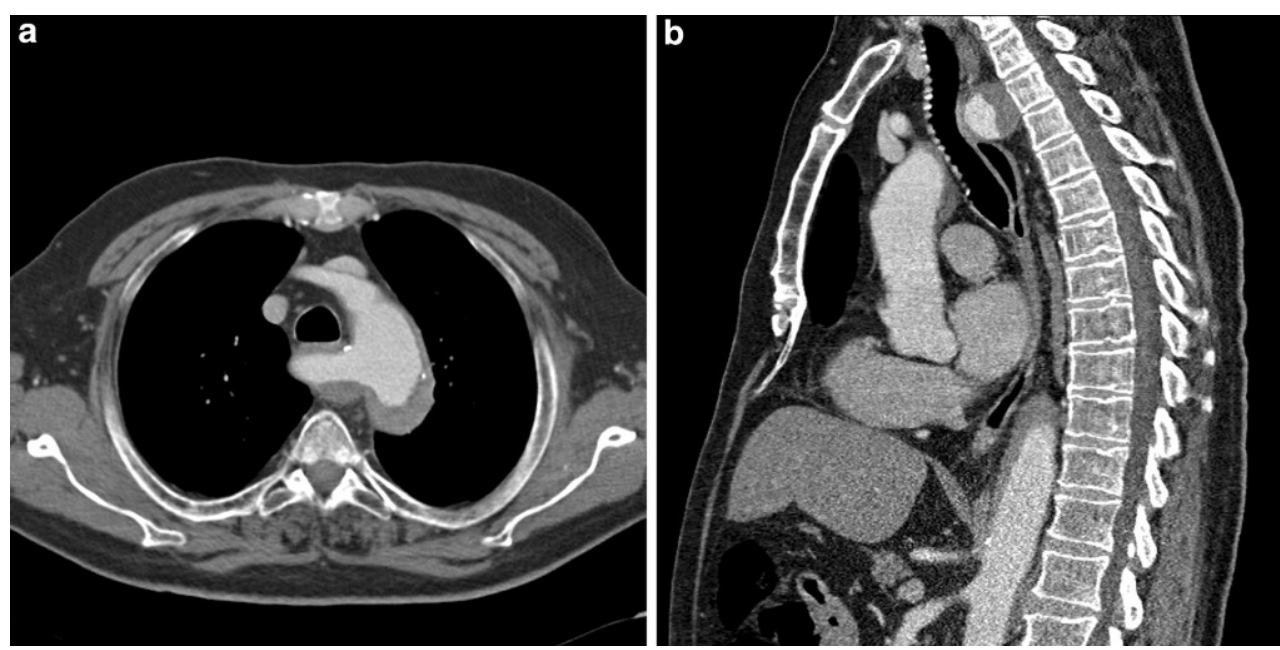

M. Boulaksil

m.boulaksil@gmail.com

1 Department of Cardiology, Radboud University Medical Center, Nijmegen, The Netherlands

2 Department of Cardiology, Jeroen Bosch Hospital, 's-Hertogenbosch, The Netherlands 